\title{
One year VARC-2-defined clinical outcomes after transcatheter aortic valve implantation with the SAPIEN 3
}

\author{
Costanza Pellegrini ${ }^{1} \cdot$ Tobias Rheude $^{1} \cdot$ Teresa Trenkwalder $^{1} \cdot$ N. Patrick Mayr ${ }^{2} \cdot$ Michael Joner $^{1,3} \cdot$ Adnan Kastrati $^{1,3}$. \\ Heribert Schunkert ${ }^{1,3} \cdot$ Oliver Husser $^{1,4} \cdot$ Christian Hengstenberg $^{1,3,5}$
}

Received: 14 September 2018 / Accepted: 19 March 2019 / Published online: 2 May 2019

(c) The Author(s) 2019

\begin{abstract}
Aims To evaluate 1-year outcome after transcatheter aortic valve implantation (TAVI) using the SAPIEN 3 (S3) prosthesis with emphasis on the composite endpoints "clinical efficacy after 30 days" and "time-related valve safety" proposed by the updated Valve Academic Research Consortium (VARC-2).

Methods and results Four hundred and two consecutive patients undergoing transfemoral TAVI with the S3 were enrolled. Mean age was $81 \pm 6$ years, $43 \%$ were female and median logistic EuroSCORE I was 12\% [8-19]. Device success was achieved in 93\% (374/402) with moderate or severe paravalvular leakage (PVL) in 2\%. At 1 year all-cause mortality was 8.9\% [95\% CI 6.4-12.2] and new permanent pacemaker implantation rate was $16 \%$ [95\% CI 12.7-20.4]. The composite endpoint time-related valve safety occurred in $29 \%$ with structural valve deterioration, defined as elevated gradients or more than moderate PVL, occurring in 13\%. The clinical efficacy endpoint after 30 days was observed in $37 \%$ of patients with the main contributor symptom worsening with New York Heart Association functional class III + in 17\% of cases.

Conclusions For the first time, VARC-2-defined composite endpoints at 1 year are reported and reveal a considerable proportion of patients experiencing the endpoint of time-related valve safety (29\%) and clinical efficacy after 30 days $(37 \%)$.
\end{abstract}

Keywords Aortic valve stenosis · Transfemoral transcatheter aortic valve implantation · VARC-2 $\cdot$ Outcome $\cdot$ SAPIEN 3

Oliver Husser and Christian Hengstenberg share the last authorship.

Electronic supplementary material The online version of this article (https://doi.org/10.1007/s00392-019-01461-7) contains supplementary material, which is available to authorized users.

Christian Hengstenberg

christian.hengstenberg@gmail.com

1 Klinik für Herz- und Kreislauferkrankungen, Deutsches Herzzentrum München, Technical University Munich, Lazarettstrasse 36, 80636 Munich, Germany

2 Institut für Anästhesiologie, Deutsches Herzzentrum München, Technical University Munich, Munich, Germany

3 Deutsches Zentrum für Herz- und Kreislauf-Forschung (DZHK) e.V. (German Center for Cardiovascular Research), Partner Site Munich Heart Alliance, Munich, Germany

4 Department of Internal Medicine I, Cardiology, St. Johannes-Hospital, Dortmund, Germany

5 Division of Cardiology, Department of Internal Medicine II, Medical University of Vienna, Vienna, Austria

\section{Introduction}

Transcatheter aortic valve implantation (TAVI) has revolutionized the treatment of symptomatic severe aortic stenosis in patients at intermediate or high risk for conventional surgical aortic valve replacement $[1,2]$. With increasing operator experience, improved patient selection but also continuous evolution of transcatheter heart valves (THV) and refinement of delivery systems a considerable improvement in outcome has been achieved with a reduction in 1-year mortality from $24 \%$ with older generation THV [3] to $12 \%$ with newer generations [2].

In the case of the latest generation balloon-expandable THV, the SAPIEN 3 (S3, Edwards Lifescience, Irvine, Ca) initial results from single centres have been promising [4, 5]. Early clinical results of the Placement of Aortic Transcatheter Valves (PARTNER) II SAPIEN 3 trial have shown low 30-day mortality and low rates of stroke or paravalvular leakage (PVL) with the S3-THV [6].

Recently, longer follow-up of the PARTNER trial and the SOURCE 3 registry have become available and have 
confirmed excellent clinical outcome up to 1 year [7, 15]. However, the available 1-year data on this THV is limited by the fact that no study has evaluated outcomes according to the updated definitions proposed by the valvular academic research consortium (VARC-2) [9]. In these, important long-term composite endpoints regarding clinical efficacy and valve safety have been proposed. Therefore, we report 1-year outcome of a large cohort of patients treated with the S3-THV at a single centre using VARC-2 criteria and for the first time report the composite endpoints at 1 year.

\section{Methods}

\section{Patient population}

All patients undergoing transfemoral TAVI for severe native aortic valve stenosis with the S3-THV between January 2014 until November 2015 at the Department of Cardiology, Deutsches Herzzentrum München, Munich, Germany were included in the present analysis $(n=402)$. A multidisciplinary heart team assessed all cases taking into account the calculated perioperative risk scores as well as the patients' characteristics at the bedside and consensus regarding the therapeutic strategy was achieved. Written informed consent was obtained prior to procedure for all patients. The 30-day outcome of a subset of the present population has been published previously [4] and for the present analysis follow-up was extended and more patients were included.

\section{Echocardiography and multislice computed tomography (MSCT) data analysis}

MSCT was performed as part of the standard pre-procedural screening protocol. Aortic annulus measurements were assessed in multiple plane reconstructions as previously described [10]. Transthoracic echocardiography was performed before TAVI, before discharge and during follow-up at 30 days and 1 year. Data at discharge, 30 days and 1 year were available for $98.3 \%, 91.5 \%$ and $91.8 \%$ of surviving patients, respectively.

\section{Prosthesis size selection and procedure}

The technical features of the S3-THV have been described elsewhere [11]. At the time of the study, the S3-THV was available in 23, 26, and $29 \mathrm{~mm}$ sizes. The final decision on implanted prosthesis size was left at the discretion of the physicians performing the procedure based on MSCT measurements, calcification and annulus eccentricity. Postdilatation was performed in case of PVL II + or in case of prosthesis underexpansion.

\section{Definition of endpoints and follow-up}

All data up to 1 year were prospectively collected during routine ambulatory visits at our outpatients' clinic, by referring to the treating physician or other hospital documentation. Clinical endpoints were categorized using VARC-2 criteria [9]. In brief, device success was defined as absence of procedural mortality and correct positioning of a single prosthetic heart valve into the proper anatomical location and intended performance. The composite endpoint early safety at 30 days [all-cause mortality, stroke (disabling and non-disabling), life-threatening bleeding, acute kidney injury (RIFLE Stage 2 or 3 or renal replacement therapy), coronary artery obstruction requiring intervention, major vascular complication, valve-related dysfunction requiring repeat procedure] was evaluated. "Time-related valve safety" is composed of structural valve deterioration, prosthetic valve endocarditis or thrombosis, stroke and bleeding. "Clinical efficacy after 30 days" consists of all-cause mortality, disabling or non-disabling stroke, or hospitalizations for valve-related symptoms or worsening congestive heart failure (CHF). Additionally, two composite endpoints, death or readmission for heart failure and death or stroke were analyzed. Follow-up at 1 year was complete for 97.5\% (392/402) and patients were censored at last event free contact.

\section{Statistical analysis}

Continuous variables are expressed as mean with the standard deviation or the median with the interquartile range. The VARC-2 composite endpoint was assessed as time-to-event rates as were each single contributor of the composite endpoint. Additionally, to allow for assessment of possible temporal changes in categories of New York Heart Association (NYHA) functional class, transvalvular gradients and PVL during follow-up, river plots were employed. Event rates were calculated as Kaplan-Meier estimates with the respective $95 \%$ confidence intervals. A two-sided $p$ value of $<0.05$ was considered statistically significant for all analyses. $\mathrm{R}$ (version 3.3.2) was used for all analyses.

\section{Results}

\section{Patient population and in-hospital outcome}

The baseline characteristics of the study population are displayed in Table 1 . Mean age was $81 \pm 6$ years, $43 \%$ were female and median logistic EuroSCORE was 12\% [8-19]. Table 2 shows procedural characteristics and in-hospital outcome. The procedure was performed using conscious 
Table 1 Baseline characteristics

\begin{tabular}{ll}
\hline & $\begin{array}{l}\text { Total patients } \\
(n=402)\end{array}$ \\
\hline Age (years) & $81 \pm 6$ \\
Female gender & $173(43)$ \\
Logistic EuroSCORE I & $12[8-19]$ \\
EuroSCORE II & $4[3-7]$ \\
Society of thoracic surgeons score & $4.3[2.7-6.6]$ \\
New York Heart Association class III/IV & $248(62)$ \\
Chronic obstructive pulmonary disease & $58(14)$ \\
Diabetes mellitus & $124(31)$ \\
Glomerular filtration rate (ml/min) & $54 \pm 22$ \\
Peripheral vascular disease & $53(13)$ \\
Previous stroke major/minor & $39(10)$ \\
Previous pacemaker & $41(10)$ \\
Previous myocardial infarction & $41(10)$ \\
Previous percutaneous coronary intervention & $170(42)$ \\
Previous coronary artery bypass graft & $24(6)$ \\
Echocardiographic characteristics & \\
Left ventricular ejection fraction $<35 \%$ & $40(10)$ \\
Mean transaortic gradient (mmHg) & $44 \pm 16$ \\
Pulmonary arterial pressure $\geq 60 \mathrm{mmHg}$ & $34(9)$ \\
\hline
\end{tabular}

All data are mean \pm standard deviation, median [interquartile range] or absolute number (percentage)

sedation in $51 \%$ of the cases. The $23 \mathrm{~mm}, 26 \mathrm{~mm}$ and $29 \mathrm{~mm}$ device was used in $41 \%, 38 \%$ and $21 \%$ of the cases, respectively. Pre-dilation was performed in the majority of cases (98\%) while post-dilatation was required in $38 \%$ of procedures. Device success was achieved in $93 \%$ with PVL II + occurring in $2 \%$ (Table 2 depicts individual contributors of device success). In-hospital mortality was $0.5 \%$.

\section{Clinical outcomes during 1 year after TAVI}

All-cause mortality at 30 days was $0.8 \%$ and increased to $8.9 \%$ at 1 year (Table 3 ; Fig. 1 ). At 30 days and 1 year, rate of readmission for CHF was $2.5 \%$ and $12.0 \%$, respectively. The 1-year composite of all-cause death or readmission for CHF was 18\% (Fig. 1a). Cumulative stroke rate at 1 year was $5 \%$ with $2 \%$ occurring within the first 30 days. The 1 -year composite of all-cause death or stroke was $12 \%$ (Fig. 1b). The cumulative incidence of permanent pacemaker implantations (PPI) in pacemaker-naive patients was $12.8 \%$ at 30 days and increased to $16.2 \%$ at 1 year.

\section{Temporal course of NYHA class}

Figure 2 shows the river plot of changes in NYHA categories. Overall, $52 \%$ and $55 \%$ of the patients were asymptomatic (NYHA I) at 30 days and 1 year, respectively. Within
Table 2 Procedural characteristics and in-hospital complications

\begin{tabular}{|c|c|}
\hline & $\begin{array}{l}\text { Total patients } \\
(n=402)\end{array}$ \\
\hline \multicolumn{2}{|l|}{ Procedural characteristics } \\
\hline Conscious sedation & $203(51)$ \\
\hline Pre-dilatation & $392(98)$ \\
\hline Post-dilatation & $154(38)$ \\
\hline Procedural time (min) & $58 \pm 29$ \\
\hline Contrast (ml) & $118 \pm 58$ \\
\hline Fluoroscopy time (min) & $13 \pm 6$ \\
\hline Device success ${ }^{\mathrm{a}}$ & $374(93)$ \\
\hline Procedural mortality & $2(0.5)$ \\
\hline Correct position & $400(99.5)$ \\
\hline Intended performance ${ }^{b}$ & $378(94)$ \\
\hline PVL II + & $8(2)$ \\
\hline Elevated gradient $(\geq 20 \mathrm{mmHg})$ & $13(3)$ \\
\hline Multiple valves & $4(1)$ \\
\hline Conversion & $3(0.7)$ \\
\hline \multicolumn{2}{|l|}{ In-hospital characteristics } \\
\hline Days on Intensive Care Unit & $1[1-2]$ \\
\hline Days in hospital & $5[4-6]$ \\
\hline ln-hospital mortality & $2(0.5)$ \\
\hline All stroke & $8(2)$ \\
\hline Major vascular complication & $31(8)$ \\
\hline Life-threatening bleeding & $20(5)$ \\
\hline Renal failure (AKIN 2/3, including dialysis) & $12(3)$ \\
\hline Coronary artery obstruction w/PCI & $1(0.2)$ \\
\hline Myocardial infarction & $1(0.2)$ \\
\hline
\end{tabular}

${ }^{\mathrm{a}}$ Multiple events possible

${ }^{\mathrm{b}}$ No patient-prosthesis mismatch, mean aortic valve gradient $<20 \mathrm{mmHg}$ or peak velocity $<3 \mathrm{~m} / \mathrm{s}$, without moderate or severe prosthetic valve regurgitation of the first implanted prosthesis

1 year, $73 \%$ of patients improved at least in one functional class, $13 \%$ experienced no change and only $3 \%$ worsened. In $11.7 \%$ of cases, NYHA class at 1 year was not available due to death $(8.5 \%)$ or was missing $(3.2 \%)$.

\section{Echocardiographic follow-up}

Mean transaortic gradients before TAVI, at discharge and during follow-up are displayed in Online Resource 1, showing stable mean gradients around $12 \mathrm{mmHg}$. The proportion of patients with elevated gradients ( $\geq 20 \mathrm{mmHg}$ ) and moderate PVL and its course during follow-up is depicted in Fig. 3. Of patients with complete echocardiography at discharge and 30 days or with known mortality status $(n=364)$, PVL was moderate in $2 \%$ at discharge and $1 \%$ at 1 year. There was no patient with severe PVL (Fig. 3a). The proportion of patients with elevated gradients was 3.3\%, 2.7\% and 9\% at discharge, 30 days and 1 year, respectively. Patients with elevated gradients at discharge had significantly smaller 
Table 3 Cumulative Kaplan-Meier event rates at 30 days and at 1 year

\begin{tabular}{|c|c|c|c|c|}
\hline & 30 days & & 1 year & \\
\hline & $\begin{array}{l}\text { KM estimate } \\
(\%)[95 \% \mathrm{CI}]\end{array}$ & Events $(n)$ & $\begin{array}{l}\text { KM estimate } \\
(\%)[95 \% \mathrm{CI}]\end{array}$ & Events $(n)$ \\
\hline All-cause mortality & $0.8[0.2-2.3]$ & 3 & $8.9[6.4-12.2]$ & 34 \\
\hline Cardiac mortality & $0.75[0.24-2.31]$ & 3 & $5.2[3.66-8.40]$ & 21 \\
\hline All stroke & $2.0[1.0-4.0]$ & 8 & $5.0[3.2-7.8]$ & 19 \\
\hline Major vascular complication & $7.8[5.5-10.9]$ & 31 & $8.3[6.0-11.5]$ & 33 \\
\hline Life-threatening bleeding & $6.0[4.1-8.8]$ & 24 & $9.0[6.6-12.3]$ & 35 \\
\hline Renal failure (AKIN 2/3, including dialysis) & $3.0[1.7-5.2]$ & 12 & $3.6[2.1-5.9]$ & 14 \\
\hline Percutaneous coronary intervention & $0.3[0.04-1.8]$ & 1 & $1.9[0.9-3.9]$ & 7 \\
\hline Myocardial infarction & $0.3[0.04-1.8]$ & 1 & $1.4[0.6-3.2]$ & 5 \\
\hline New permanent pacemaker implantation ${ }^{\mathrm{a}}$ & $12.8[9.8-16.7]$ & 46 & $16.2[12.7-20.4]$ & 57 \\
\hline Valve-related dysfunction w/ BAV, TAVR or SAVR & 0 & 0 & $0.3[0.04-1.9]$ & 1 \\
\hline Valve-related dysfunction ${ }^{\mathrm{b}}$ & $5.4[3.5-8.1]$ & 21 & $20.6[15.3-27.5]$ & 52 \\
\hline Endocarditis & 0 & 0 & $1.9[0.9-4.0]$ & 7 \\
\hline Congestive heart failure w/ hospitalization & $2.5[1.4-4.6]$ & 10 & $12.0[9.1-15.7]$ & 45 \\
\hline Early safety (at 30 days) ${ }^{\mathrm{b}}$ & $13.7[10.7-17.4]$ & 55 & - & - \\
\hline Clinical efficacy (after 30 days) ${ }^{\mathrm{b}}$ & - & - & $37.2[32.2-42.7]$ & 133 \\
\hline Time-related valve safety ${ }^{\mathrm{b}}$ & $12.8[9.9-16.5]$ & 51 & $29.4[24.7-34.7]$ & 105 \\
\hline
\end{tabular}

$A K I N$ acute kidney injury, BAV balloon aortic valvuloplasty, SAVR surgical aortic valve replacement, TAVR transcatheter aortic valve replacement

${ }^{\text {a } O n l y ~ p a c e m a k e r-n a i v e ~ p a t i e n t s ~}$

${ }^{\mathrm{b}}$ For definition of composite endpoints, see Methods

Fig. 1 Cumulative incidence of death and CHF (a) and death and stroke (b). Kaplan-Meier failure curves for the cumulative event rate of death and/or $\mathrm{CHF}$ (a) and death and/or stroke (b) during the first year after TAVI

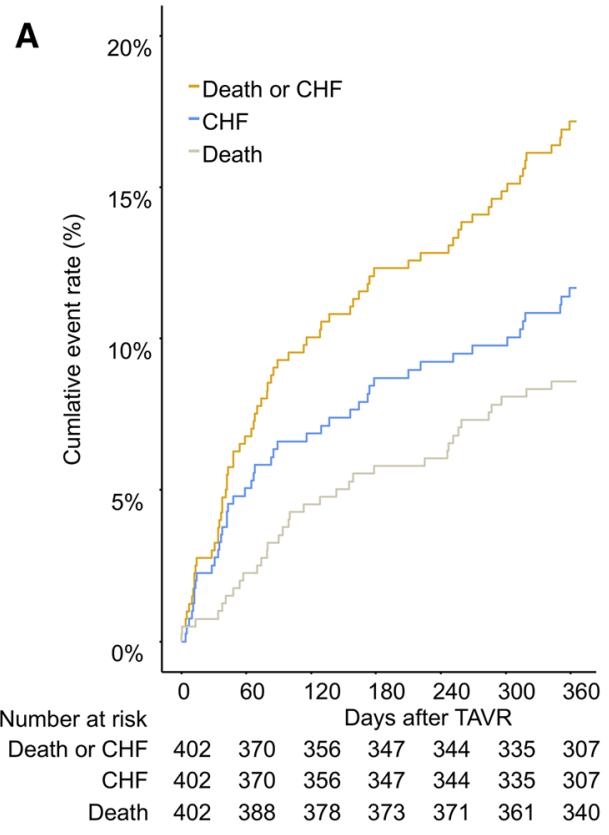

aortic annuli compared to those without elevated gradients $\left(3.7 \pm 0.5\right.$ vs. $\left.4.8 \pm 0.9 \mathrm{~cm}^{2} ; p<0.001\right)$, were more often female ( $84.6 \%$ vs. $41.6 \% ; p=0.002)$ and were all treated with the $23 \mathrm{~mm}$ prosthesis. Figure $3 \mathrm{~b}$ shows a considerable increase in elevated gradients from 30 days to 1 year.

\section{VARC-2-defined composite endpoints}

The combined early safety endpoint at 30 days occurred in $13.7 \%$. During the first year after TAVI, $29.4 \%$ experienced the time-related valve safety endpoint (Table 3 ). Figure $4 \mathrm{a}$ 


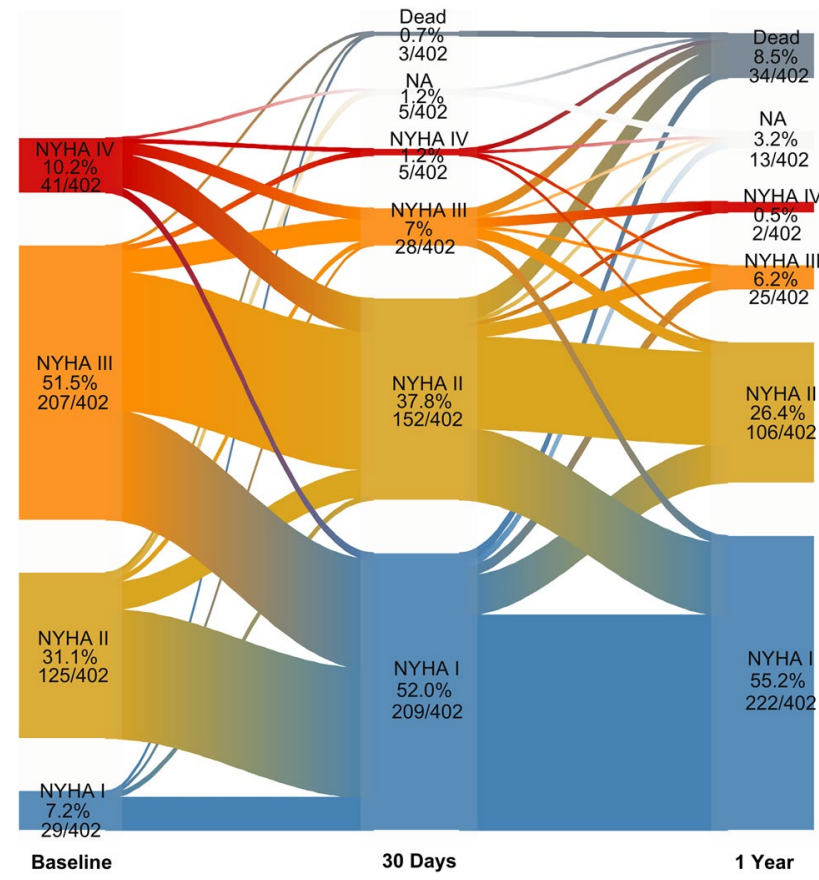

Fig. 2 New York Heart Association Functional Class at baseline and during follow-up. Change in NYHA categories during the first year after TAVI

A

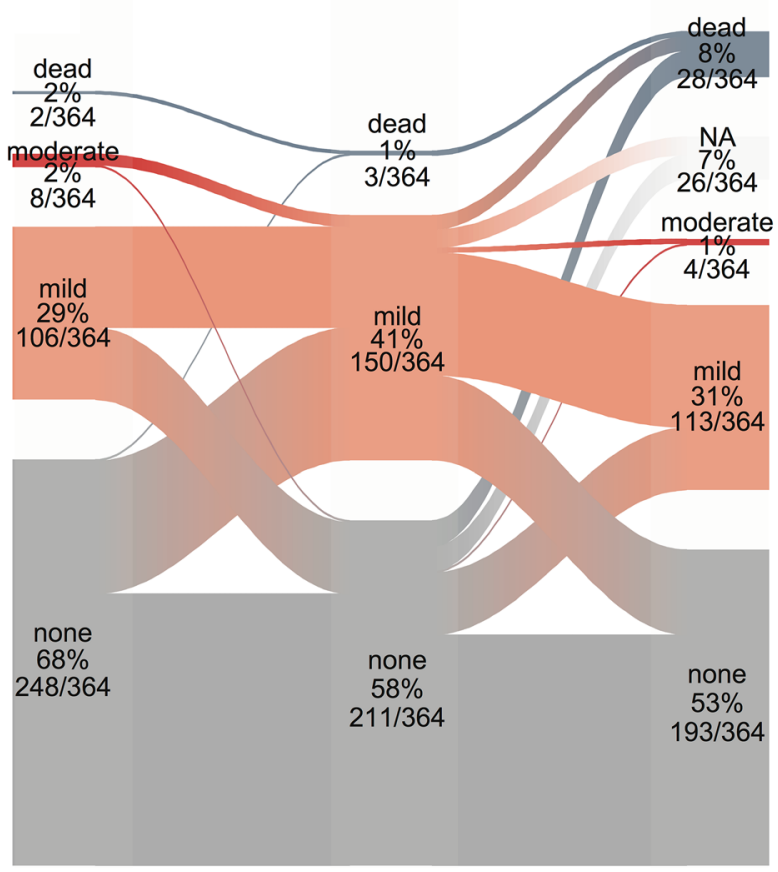

Discharge

30 Days

1 Year

Fig. 3 Echocardiographic valve performance after discharge for PVL (a) and transvalvular gradients (b). Change in PVL (a) and elevated gradients during the first year after TAVI. Note that only patients shows the individual contributors to this endpoint, the main contributor being structural valve deterioration, defined as elevated gradients ( $\geq 20 \mathrm{mmHg}$ ) or PVL II + with a cumulative incidence of $12.9 \%$ at 1 year. The clinical efficacy endpoint after 30 days was observed in $37.2 \%$ (Fig. 4b). The main contributor of this composite endpoint was symptom worsening (NYHA III/IV) with a cumulative incidence of $17.2 \%$.

\section{Discussion}

In a contemporary population of TAVI patients who were treated in a single centre with the S3-THV, we found excellent results for 1-year mortality. For the first time, we report VARC-2-defined composite endpoints at 1 year, namely "clinical efficacy after 30 days" and "time-related valve safety".

\section{The VARC endpoint definitions-1-year on the SAPIEN 3 transcatheter heart valve}

The updated Valve Academic Research Consortium criteria provide a standardized framework for evaluation and comparison of clinical outcomes after TAVI [9]. Although

B

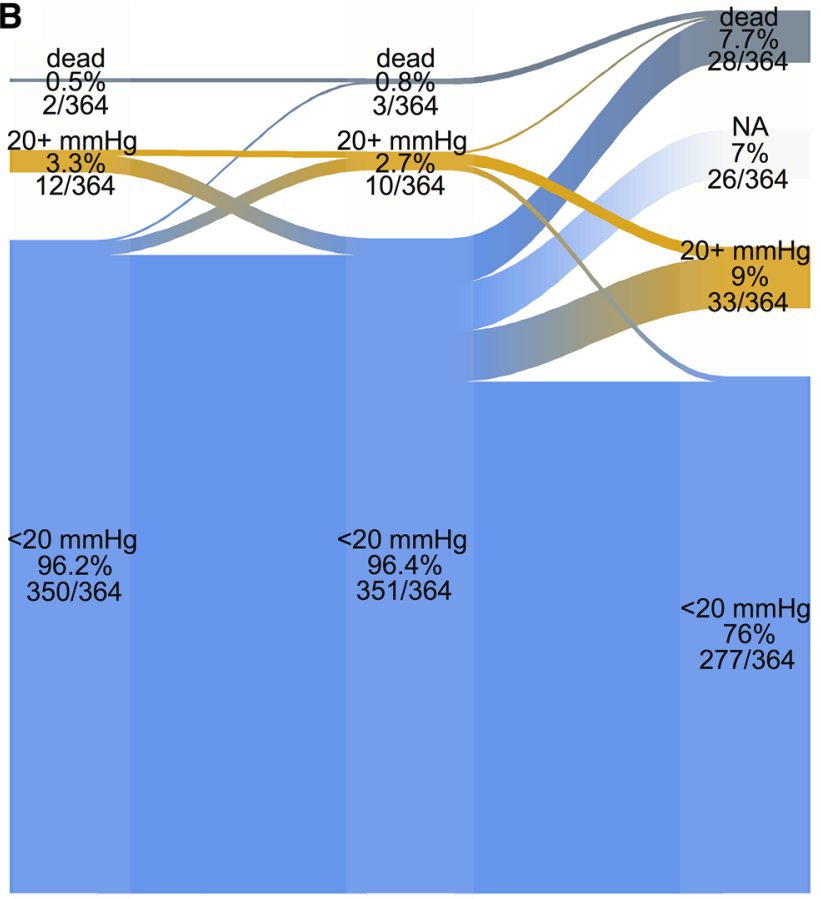

Discharge

30 Days

1 Year

with complete echocardiography at discharge and 30 days or dead $(n=364)$ are displayed 

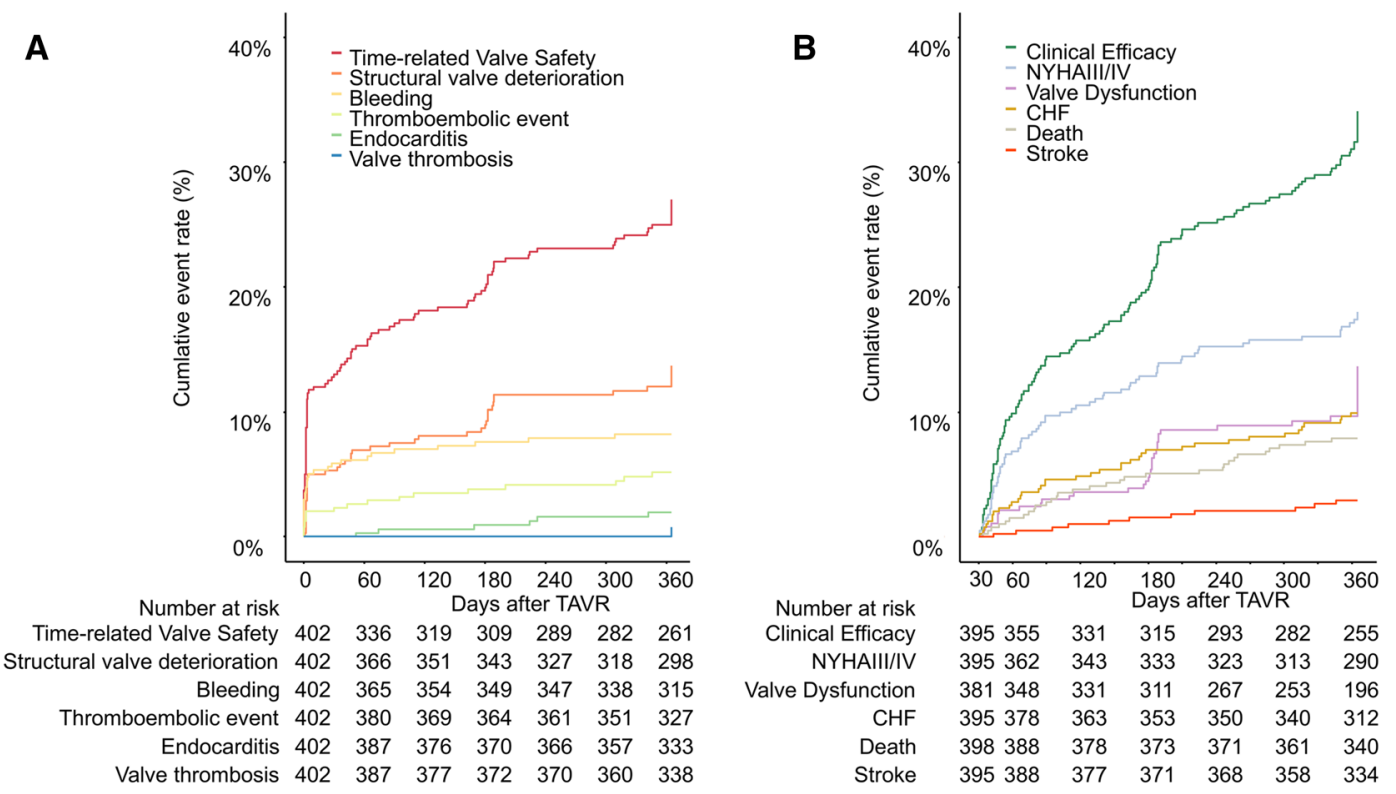

Fig. 4 VARC-2 composite endpoints: time-related valve safety (a) and clinical efficacy after 30 days (b). Kaplan-Meier failure curves for the cumulative event rates of time-related valve safety (a) and clinical efficacy after 30 days (b) with rates of their respective contributors

the adoption of VARC criteria has been increasing over time, a considerable number of publications does not report outcomes according to VARC $[12,13]$. Indeed, even in recent pivotal TAVI trials, while applying VARC-2 criteria for reporting in-hospital outcomes, important composite endpoints such as device success and early safety at 30 days are not reported [6-8].

The S3-THV is widely used, however, relatively little data on 1-year results is available and no data at all is available on the VARC-2 composite endpoints. The majority of data come from the PARTNER II trial [6], in which 952 patients treated transfemorally from the intermediaterisk population presented an all-cause mortality of $12.3 \%$ and the combined rate of all-cause mortality and stroke was $17.2 \%$ at 1 year [14]. Recently, 1-year data from the SOURCE 3 and the Israeli TAVR registry showed even lower all-cause mortality rates at 1 year ranging from 8.5 to $12.6 \%$ and a stroke rate of $3.1 \%[15,16]$. A recent subgroup analysis of the SOURCE 3 registry showed mortality rates of $9.3 \%$ in patients aged $75-80$ years [17], while Eichler et al. [18] presented all-cause mortality rates of $13.8 \%$ at 1 year. Our results from 402 patients are comparable favourably to this recent 1 -year data with an allcause mortality of $8.9 \%$ and stroke rate of $5.0 \%$.

Very recently, results from randomized trials of a lowrisk TAVI population have been published in the New England Journal of Medicine, showing even lower 1-year mortality rates ranging from $1-2.4 \%[19,20]$. These promising results further strengthen the positive results of TAVI and encourage to a further expansion to a younger and low-risk population.

\section{VARC-2 composite endpoints}

The composite endpoint "device success" is an important measure of acute procedural success and few studies have assessed this using the S3-THV. Our group has previously published 30-day outcomes using the S3-THV [4]. In this extended analysis with 1-year follow-up and a significant increase in sample size, we were able to show stable rates of device success (93\% vs. $97.6 \%$ ) and early safety at 30 days ( $13.7 \%$ vs. $10 \%)$. As far as clinical efficacy after 30 days and time-related valve safety is concerned, little data are available in the current literature and with other THV [21]. In the present study, we found a relatively high incidence of these endpoints mostly driven by symptomatic heart failure (NYHA class III/IV) or valve-related dysfunction with elevated gradients.

Frequently, clinical conclusions are drawn from comparison of summary data. From those, it is almost impossible to follow the development of certain parameters. Here, we created river plots for NYHA class and echocardiographic parameters to better understand the effects of TAVI on both, the individual and the population. Using a river plot-based analysis, we observed a dynamic change in elevated gradients calling into question the clinical significance of this finding. Although the mean of mean pressure gradients was low throughout the first year $(12 \mathrm{mmHg})$, a considerable 
proportion of patients (9\%) exhibited elevated gradients at 1 year. Other groups have reported even higher rates of patient-prosthesis mismatch (24\%) mostly due to elevated gradients with the S3-THV [22]. In this analysis, patients experiencing elevated gradients displayed no significant difference in outcome in terms of mortality, stroke rates or worsening of symptoms. A previous study on surgical aortic valve replacement suggested higher rates of re-intervention in patients with elevated gradients, especially in younger patients [23]. Moving towards a younger TAVI population, assessing the impact of elevated gradients on valve durability is of the utmost importance and future studies in large populations with extended follow-up are warranted to fully assess the significance of this finding.

Recently, it has become evident that not only valve deterioration but also valve thrombosis does contribute to elevated gradients [24]. Subclinical leaflet thrombosis, a phenomenon relatively recently recognized in the field of TAVI [25], may be a possible explanation for the considerable dynamic in the rate of elevated gradients. In the current analysis, we detected only three cases of valve thrombosis; however, this population treated from 2014 to 2015 was not routinely screened for valve thrombosis with serial examinations by CT or transesophageal echocardiography. Hence, the incidence of valve thrombosis may be underestimated and cannot be excluded as temporary or longer lasting cause of elevated gradients.

\section{New permanent pacemaker implantations}

Cardiac conduction disturbances leading to PPI are a frequent and important complication after TAVI. Although earlier investigations found no negative effect of new PPI on outcome [26], recent data have identified chronic pacing as independent predictor of 1-year mortality after TAVI and as an important cause of prolonged hospital stay [27].

In the case of the S3-THV, first systematic data on PPI showed incidences of $13 \%$ until up to $25.5 \%$ [28-30]. This led to several investigations examining in more detail the potential underlying mechanisms and demonstrated PPI rates of $11.6 \%$ [14], 13.1\% [6], and $16 \%$ [10] at 30 days in pacemaker-naive patients. Multiple factors have been described to predict PPI following TAVI, especially a previous right bundle branch block [31-33]. In an extended meta-analysis of PPI following TAVI, Siontis et al. [34] categorized these factors into patient-related, electrocardiographic and procedural factors. While the former two categories cannot be influenced by the operator's choices or skills, device-related factors may be influenced by sizing strategies, implantation technique and implantation depth. Development of novel devices should particularly address these "modifiable" features to allow for less need of PPI after TAVI.

\section{Limitations}

This is an observational study from a single centre without centre-independent adjudication of postprocedural results and lack of independent echocardiographic core lab assessment. Clinical benefit was assessed by NYHA functional class and may be patients' subjective perception.

\section{Conclusions}

The present study assesses 1-year outcomes with the S3-THV according to VARC-2-defined endpoints with low rates of mortality and stroke at 1 year. For the first time, VARC-2-defined composite endpoints at 1 year are reported and reveal a considerable proportion of patients experiencing the composite endpoint of time-related valve safety (29\%) and clinical efficacy after 30 days (37\%). The main contributor to these combined endpoints was elevated gradients. Further research is warranted to reveal the underlying mechanisms behind this observation.

Acknowledgements Open access funding provided by Medical University of Vienna.

Funding No funding was received for this study.

\section{Compliance with ethical standards}

Conflict of interest Dr. Hengstenberg received Proctor fees and speaker honoraria from Edwards Lifesciences. Drs. Husser and Pellegrini received minor travel grants from Edwards Lifesciences. All the other authors have nothing to disclose.

Ethical approval All the procedures performed in studies involving human participants were in accordance with the ethical standards of the institutional and/or national research committee and with the 1964 Helsinki Declaration and its later amendments or comparable ethical standards. All patients gave their informed consent prior to the inclusion in the study.

Open Access This article is distributed under the terms of the Creative Commons Attribution 4.0 International License (http://creativeco mmons.org/licenses/by/4.0/), which permits unrestricted use, distribution, and reproduction in any medium, provided you give appropriate credit to the original author(s) and the source, provide a link to the Creative Commons license, and indicate if changes were made.

\section{References}

1. Smith CR, Leon MB, Mack MJ et al (2011) Transcatheter versus surgical aortic-valve replacement in high-risk patients. N Engl J Med 364:2187-2198 
2. Leon MB, Smith CR, Mack MJ et al (2016) Transcatheter or surgical aortic-valve replacement in intermediate-risk patients. N Engl J Med 374:1609-1620

3. Holmes DR Jr, Brennan JM, Rumsfeld JS et al (2015) Clinical outcomes at 1 year following transcatheter aortic valve replacement. JAMA 313:1019-1028

4. Husser O, Pellegrini C, Kessler T et al (2015) Outcomes after transcatheter aortic valve replacement using a novel balloonexpandable transcatheter heart valve: a single-center experience. JACC Cardiovasc Interv 8:1809-1816

5. Frangieh AH, Ott I, Michel J et al. (2017) Standardized minimalistic transfemoral transcatheter aortic valve replacement (TAVR) using the SAPIEN 3 device: stepwise description, feasibility, and safety from a large consecutive single-center single-operator cohort. Struct Heart 1:1-10

6. Kodali S, Thourani VH, White J et al (2016) Early clinical and echocardiographic outcomes after SAPIEN 3 transcatheter aortic valve replacement in inoperable, high-risk and intermediate-risk patients with aortic stenosis. Eur Heart J 37:2252-2262

7. Herrmann HC, Thourani VH, Kodali SK et al (2016) One-year clinical outcomes with SAPIEN 3 transcatheter aortic valve replacement in high-risk and inoperable patients with severe aortic stenosisclinical perspective. Circulation 134:130-140

8. Wendler O, Schymik G, Treede $\mathrm{H}$ et al (2017) SOURCE 3 registry: design and 30-day results of the European postapproval registry of the latest generation of the SAPIEN 3 transcatheter heart valve. Circulation 135:1123-1132

9. Kappetein AP, Head SJ, Généreux P et al (2012) Updated standardized endpoint definitions for transcatheter aortic valve implantation: the valve academic research consortium- 2 consensus document. J Am Coll Cardiol 60:1438-1454

10. Husser O, Pellegrini C, Kessler T et al (2016) Predictors of permanent pacemaker implantations and new-onset conduction abnormalities with the SAPIEN 3 balloon-expandable transcatheter heart valve. JACC Cardiovasc Interv 9:244-254

11. Binder RK, Rodés-Cabau J, Wood DA et al (2013) Transcatheter aortic valve replacement with the SAPIEN 3: a new balloonexpandable transcatheter heart valve. JACC Cardiovasc Interv 6:293-300

12. Erlebach M, Head SJ, Mylotte D et al (2016) VARC endpoint definition compliance rates in contemporary transcatheter aortic valve implantation studies. Euro Interv 12:375-380

13. Zhang S, Kolominsky-Rabas PL (2017) How TAVI registries report clinical outcomes-a systematic review of endpoints based on VARC-2 definitions. PLoS One 12:e0180815

14. Thourani VH, Kodali S, Makkar RR et al (2016) Transcatheter aortic valve replacement versus surgical valve replacement in intermediate-risk patients: a propensity score analysis. Lancet 387:2218-2225

15. Wendler O, Schymik G, Treede $\mathrm{H}$ et al (2017) SOURCE 3: 1-year outcomes post-transcatheter aortic valve implantation using the latest generation of the balloon-expandable transcatheter heart valve. Eur Heart J 38:2717-2726

16. Finkelstein A, Steinvil A, Rozenbaum Z et al (2018) Efficacy and safety of new-generation transcatheter aortic valves: insights from the Israeli transcatheter aortic valve replacement registry. Clin Res Cardiol. https://doi.org/10.1007/s00392-018-1372-6

17. Frank D, Abdel-Wahab M, Gilard M et al (2018) Characteristics and outcomes of patients $\leq 75$ years who underwent transcatheter aortic valve implantation: insights from the SOURCE 3 Registry. Clin Res Cardiol. https://doi.org/10.1007/s00392-018-1404-2

18. Eichler S, Salzwedel A, Harnath A et al (2018) Nutrition and mobility predict all-cause mortality in patients 12 months after transcatheter aortic valve implantation. Clin Res Cardiol 107:304-311

19. Popma JJ, Deeb GM, Yakubov SJ et al (2019) Transcatheter aortic-valve replacement with a self-expanding valve in low-risk patients. N Engl J Med. https://doi.org/10.1056/NEJMoa1816885

20. Mack MJ, Leon MB, Thourani VH et al (2019) Transcatheter aortic-valve replacement with a balloon-expandable valve in lowrisk patients. N Engl J Med. https://doi.org/10.1056/NEJMoa1814 052

21. Pellegrini C, Rheude T, Trenkwalder T et al (2019) One-year clinical outcome with a novel self-expanding transcatheter heart valve. Catheter. Cardiovasc Interv. https://doi.org/10.1002/ccd.28144

22. Pilgrim T, Stortecky S, Nietlispach F et al. (2016) Repositionable versus balloon-expandable devices for transcatheter aortic valve implantation in patients with aortic stenosis. J Am Heart Assoc. https://doi.org/10.1161/JAHA.116.004088

23. Vohra HA, Whistance RN, de Kerchove L, Glineur D, Noirhomme P, El Khoury G (2013) Influence of higher valve gradient on longterm outcome after aortic valve repair. Ann Cardiothorac Surg 2:30-39

24. Hein M, Minners J, Jander N et al (2019) Haemodynamic prosthetic valve performance in patients with early leaflet thrombosis after transcatheter aortic valve implantation. Clin Res Cardiol. https://doi.org/10.1007/s00392-019-01429-7

25. Makkar RR, Fontana G, Jilaihawi H et al (2015) Possible subclinical leaflet thrombosis in bioprosthetic aortic valves. N Engl J Med 373:2015-2024

26. Buellesfeld L, Stortecky S, Heg D et al (2012) Impact of permanent pacemaker implantation on clinical outcome among patients undergoing transcatheter aortic valve implantation. J Am Coll Cardiol 60:493-501

27. Nazif TM, Dizon JM, Hahn RT et al (2015) Predictors and clinical outcomes of permanent pacemaker implantation after transcatheter aortic valve replacement: The PARTNER (Placement of AoRtic TraNscathetER Valves) trial and registry. JACC Cardiovasc Interv 1 (8):60-69

28. Webb J, Gerosa G, Lefèvre T et al (2014) Multicenter evaluation of a next-generation balloon-expandable transcatheter aortic valve. J Am Coll Cardiol 64:2235-2243

29. Tarantini G, Mojoli M, Purita P et al (2015) Unravelling the (arte) fact of increased pacemaker rate with the Edwards SAPIEN 3 valve. Euro Interv 11:343-350

30. Murray M-I, Geis N, Pleger ST et al (2015) First experience with the new generation Edwards Sapien 3 aortic bioprosthesis: procedural results and short term outcome. J Interv Cardiol 28:109-116

31. Pellegrini C, Husser O, Kim W-K et al (2018) Predictors of need for permanent pacemaker implantation and conduction abnormalities with a novel self-expanding transcatheter heart valve. Rev Esp Cardiol. https://doi.org/10.1016/j.rec.2018.01.011

32. Gaede L, Kim W-K, Liebetrau C et al (2018) Pacemaker implantation after TAVI: predictors of AV block persistence. Clin Res Cardiol 107:60-69

33. Gonska B, Seeger J, Keßler M, von Keil A, Rottbauer W, Wöhrle J (2017) Predictors for permanent pacemaker implantation in patients undergoing transfemoral aortic valve implantation with the Edwards Sapien 3 valve. Clin Res Cardiol 106:590-597

34. Siontis GCM, Jüni P, Pilgrim T et al (2014) Predictors of permanent pacemaker implantation in patients with severe aortic stenosis undergoing TAVR: a meta-analysis. J Am Coll Cardiol 64:129-140 